\title{
Surface modification of interconnected porous scaffolds
}

\author{
Xiaohua Liu, ${ }^{1}$ Youngjun Won, ${ }^{1}$ Peter X. $\mathrm{Ma}^{1-3}$ \\ ${ }^{1}$ Department of Biologic and Materials Sciences, 1011 North University Ave., Room 2211, The University of Michigan, \\ Ann Arbor, Michigan 48109-1078 \\ ${ }^{2}$ Department of Biomedical Engineering, University of Michigan, Ann Arbor, Michigan 48109-1078 \\ ${ }^{3}$ Macromolecular Science and Engineering Center, University of Michigan, Ann Arbor, Michigan 48109-1078
}

Received 1 December 2004; accepted 3 January 2005

Published online 3 June 2005 in Wiley InterScience (www.interscience.wiley.com). DOI: 10.1002/jbm.a.30367

\begin{abstract}
Surface properties of scaffolds play an important role in cell adhesion and growth. Biodegradable poly $(\alpha-$ hydroxy acids) have been widely used as scaffolding materials for tissue engineering; however, the lack of functional groups is a limitation. In this work, gelatin was successfully immobilized onto the surface of poly( $\alpha$-hydroxy acids) films and porous scaffolds by a new entrapment process. The surface composition and properties were examined using attenuated total reflection-Fourier transform infrared spectroscopy (ATR-FTIR), X-ray photoelectron spectra (XPS), and contact angle measurements. Control over the amount of entrapped gelatin was achieved by varying the solvent composition, the duration of soaking, the concentration of gelatin in solution, and chemical crosslinking. The amount of entrapped gelatin increased with the ratio of dioxane/ water in the solvent mixture used. Chemical crosslinking after physical entrapment considerably increased the amount of retained gelatin on the surface of poly $(\alpha$-hydroxy
\end{abstract}

acids). Osteoblasts were cultured on these films and scaffolds. The surface modification significantly improved cell attachment and proliferation. Cell numbers on the surfacemodified films and scaffolds were significantly higher than those on controls $4 \mathrm{~h}$ and 1 day after cell seeding. The osteoblasts showed higher proliferation on surface-modified scaffolds than on the control during 4 weeks of in vitro cultivation. More collagen fibers and other cell secretions were deposited on the surface-modified scaffolds than on the control scaffolds. This novel surface treatment strategy provides a convenient and universal way to modify the surface properties of three-dimensional scaffolds and thus promote cell adhesion and proliferation for tissue engineering. (c) 2005 Wiley Periodicals, Inc. J Biomed Mater Res 74A: 84-91, 2005

Key words: entrapment; gelatin; PLGA; PLLA; scaffold; surface; tissue engineering

\section{INTRODUCTION}

The surface properties of biomaterials are a key aspect in determining compatibility with the biological environment and cellular responses. ${ }^{1-6}$ Ideally, scaffolding materials should be designed to be bioactive so that they can receive and respond to specific biological signals, which direct and promote cell attachment, proliferation, differentiation, and tissue regeneration. $^{7-10}$

$\operatorname{Poly}(\alpha$-hydroxy acids), which include poly(glycolic acid) (PGA), poly(lactic acid) (PLA) and their copolymers (PLGA), have been extensively studied as scaffolding materials for tissue regeneration. ${ }^{11-17}$ They

Correspondence to: P. X. Ma; e-mail: mapx@umich.edu

Contract grant sponsor: University of Michigan; contract grant number: Nano Materials Initiative Grant (P.X.M.)

Contract grant sponsor: National Institutes of Health; contract grant numbers: DE014755, DE015384

(c) 2005 Wiley Periodicals, Inc. have the advantage of FDA approval for certain clinical applications. They also possess good mechanical properties, low immunogenicity and toxicity, and predictable biodegradation kinetics. However, the lack of available functional groups in the polymeric chains to conjugate specific cell-recognizable signal molecules has limited their scope in tissue engineering applications.

Several approaches have been developed to circumvent this disadvantage. Simple surface coating is a general approach to adsorb the required surface-modifying species onto the polymer surface. ${ }^{18}$ However, this method requires that the surface-modifying solution spreads well on the substrate to ensure coating efficiency. The interactions between the bulk polymer and the surface-modifying species are usually weak, and thus the surface is unstable. There are more-complex coating methods involving chemical reactions. ${ }^{19-21}$ For example, a biomimetic method has been developed to grow bonelike mineral on three-dimensional (3D) porous polymer materials as scaffolds for bone tissue engineering. ${ }^{20-22}$ Another strategy is to 
introduce functional groups in the polymer chains. ${ }^{23,24}$ For example, poly(L-lactide-co-lysine) was synthesized to provide reactive amine groups in the PLA backbone for the conjugation of cell adhesion peptide arginineglycine-aspartic acid (RGD). ${ }^{24}$ These functionalized polymers, aiming at chemical modification of surface properties, alter their bulk properties as well, ${ }^{7}$ which may result in certain undesirable effects. Plasma exposure is effective for two-dimensional (2D) film surface etching. ${ }^{23,25}$ This technique can be used to introduce the desired groups or chains onto the surface of a material but is limited for a 3D scaffold with designated morphology and structure.

In this study, we introduce a simple but effective surface modification method. Gelatin was immobilized onto the surface of poly( $\alpha$-hydroxy acids) by a new entrapment procedure. Gelatin is made up of high-molecular-weight polypeptides derived from collagen, the primary protein component of connective tissues. ${ }^{26}$ Gelatin is formed by breaking the natural triple-helix structure of collagen into single-strand molecules and has been used in many tissue engineering applications because of its biocompatibility and ease of gelation. ${ }^{27-29}$ Further chemical modification of gelatin is also convenient because it contains abundant amino and carboxyl groups in the polymeric chains. The surface-modified poly(L-lactic acid) (PLLA) films and scaffolds were examined for cell adhesion and proliferation.

\section{MATERIALS AND METHODS}

\section{Materials}

Poly(L-lactic acid) and poly(lactide-co-glycolide) (85/15) (PLGA85/15) with an inherent viscosity of approximately 1.6 and 0.5-0.6, respectively, were purchased from Boehringer Ingelheim (Ingelheim, Germany) and used without further purification. Gelatin (type B, from bovine skin, approx 225 bloom), 1,4-dioxane, glutaraldehyde, osmium tetraoxide, hexamethyldisilazane (HMDS), $\beta$-glycerophosphate, neutral-buffered formalin, trypan blue, and DNA quantitation kit were purchased from Sigma Chemical Co. (St. Louis, MO). N-Hydroxy-succinimide (97\%) (NHS) and $\{2-[\mathrm{N}$-morpholino] ethanesulfonic acid $\}$ hydrate (MES) were purchased from Aldrich Chemical (Milwaukee, WI). 1-Ethyl-3-(3-dimethylaminopropyl) carbodiimide $\mathrm{HCl}$ (EDC) was purchased from Pierce Biotechnology (Rockford, IL). Fetal bovine serum, $\alpha$-minimum essential medium ( $\alpha$-MEM), penicillin-streptomycin, Dulbecco's phosphate-buffered saline (PBS), and trypsin-edetic acid (EDTA) were purchased from Gibco BRL Products, Life Technologies (Grand Island, NY). Ascorbic acid was purchased from Fisher Scientific (Pittsburgh, PA). Ethylene oxide was purchased from H.W. Anderson Products (Chapel Hill, NC).

\section{Fabrication of poly( $\alpha$-hydroxy acids) films and scaffolds}

The PLLA (0.5 g) was dissolved in 1,4-dioxane $(10 \mathrm{~mL})$ at $50^{\circ} \mathrm{C}$, and the PLLA solution was cast onto a $10 \mathrm{~cm} \times 10 \mathrm{~cm}$ Teflon mold. After solvent evaporation in a fume hood at room temperature for $24 \mathrm{~h}$, the films were removed from the mold and dried under vacuum for another $24 \mathrm{~h}$. The thickness of the film was controlled to be approximately $40 \mu \mathrm{m}$ by adjusting the concentration of PLLA solution and coverage area.

Dried PLLA films were first washed with hexane to remove possible surface contaminants and then wetted in ethanol. The ethanol-treated films were soaked in distilled water for $30 \mathrm{~min}$. Water was changed three times to ensure that ethanol was completely replaced by water.

Poly( $\alpha$-hydroxy acids) 3D scaffolds were fabricated by using paraffin as porogen as reported earlier. ${ }^{30}$ Briefly, paraffin spheres (diameter 250-420 $\mu \mathrm{m}$ ) were added to Teflon molds, and the top surface was leveled. The molds were then preheated at $37^{\circ} \mathrm{C}$ for $20 \mathrm{~min}$ to ensure that paraffin spheres were interconnected. A 10\% (w/v) PLLA/dioxane solution was cast onto paraffin sphere assemblies and vacuum-treated in a vacuum oven to remove air trapped inside the paraffin sphere assemblies. The polymer/paraffin composite was air- and vacuum-dried for 3 days, and then hexane was added to leach paraffin from the composite. Cyclohexane was exchanged with hexane. Polymer scaffolds were lyophilized and cut to samples with $7.2 \mathrm{~mm}$ diameter and $2.0 \mathrm{~mm}$ thickness. The poly( $\alpha$-hydroxy acids) scaffolds were washed with hexane followed by ethanol pretreatment before surface modification.

\section{Surface physical entrapment of gelatin}

Gelatin was dissolved in dioxane/water solvent mixture at around $50^{\circ} \mathrm{C}$. The pretreated poly ( $\alpha$-hydroxy acids) films or scaffolds were immersed in the gelatin solution for a designated time, then taken out and quickly put into $200 \mathrm{~mL}$ ice/water mixture for $10 \mathrm{~min}$. The above-treated films or scaffolds were rinsed in water at $40^{\circ} \mathrm{C}$ for $12 \mathrm{~h}$. Water was changed every $3 \mathrm{~h}$ to remove nonentrapped gelatin from the poly( $\alpha$-hydroxy acids) surface. The films or scaffolds were dried at room temperature for $24 \mathrm{~h}$ and vacuum-dried for another $24 \mathrm{~h}$.

Simple coating of poly ( $\alpha$-hydroxy acids) films or scaffolds was also performed as described above, except that distilled water instead of dioxane/water mixture was used as solvent for gelatin.

\section{Chemical crosslinking after physical entrapment}

Chemical crosslinking was performed after the surface treated poly( $\alpha$-hydroxy acids) films or scaffolds were dipped in an ice/water mixture. Crosslinking of gelatin with EDC and NHS was carried out in MES buffer (pH 5.3, $0.05 \mathrm{M})$ at $4^{\circ} \mathrm{C}$ for $24 \mathrm{~h}$. The films or scaffolds were then 
washed three times with distilled water at $4^{\circ} \mathrm{C}$, followed by rinsing at $40^{\circ} \mathrm{C}$ for $12 \mathrm{~h}$ (water was changed every $3 \mathrm{~h}$ ). The chemically crosslinked films or scaffolds were then air- and vacuum-dried for 2 days.

\section{Characterization of surface modification}

\section{X-ray photoelectron spectroscopy}

The XPS analyses were performed on a PerkinElmer model PHI 5400 XPS instrument (Physical Electronics Inc., Chanhassen, $\mathrm{MN}$ ) with a monochromatized $\mathrm{Al}$ anode operated at $300 \mathrm{~W}, 15 \mathrm{kV}$, and $20 \mathrm{~mA}$. Samples were attached to the aluminum sample platform with double-sided tapes. The take-off angle was $30^{\circ}$ with respect to sample plane. The pressure during analysis was maintained at about $10^{-9}$ Torr. Survey spectra were obtained using a passing energy of $89.45 \mathrm{eV}$, and high-resolution spectra were obtained using a passing energy of $17.90 \mathrm{eV}$. All binding energies were referenced to carbon $\mathrm{CHx}$ peaks at $285.0 \mathrm{eV}$. Quantitative analyses were performed using peak areas and elemental sensitivity factors. Element surface composition was expressed in atomic percent $(\mathrm{at} \%)$, and nitrogen $(\mathrm{N})$ was used to characterize the amount of entrapped gelatin on the surface of poly( $\alpha$-hydroxy acids).

\section{Contact angle measurements}

Contact angles were measured at room temperature with an image analyzing system (CAM100; KSV Instruments Ltd., Helsinki, Finland) using the sessile drop technique. Double-distilled water was used in the measurement. Each determination was obtained by averaging the results of at least eight droplets placed at different positions on the sample surface.

\section{ATR-FTIR analysis}

The ATR-FTIR spectra of films were obtained with a Perkin Elmer 1800 FTIR spectroscopy, in the region from 500 to $4000 \mathrm{~cm}^{-1}$. During the measurement, the sample chamber was purged with nitrogen gas to reduce moisture content. We determined the average for 1024 scans at a resolution of $4 \mathrm{~cm}^{-1}$.

\section{Cell culture}

The thawed MC3T3-E1 osteoblasts (clone 26) were cultured in a supplemented $\alpha$-MEM and $10 \%$ fetal bovine serum (FBS) containing $100 \mathrm{U} / \mathrm{mL}$ penicillin and $100 \mu \mathrm{g} / \mathrm{mL}$ streptomycin in a humidified incubator at $37^{\circ} \mathrm{C}$ with $5 \%$ $\mathrm{CO}_{2}$. The medium was changed every other day. The cells of passages 3 and 4 were seeded onto the 2D PLLA films and 3D PLLA scaffolds (control and surface-modified groups).
The viability of cells before seeding was higher than $90 \%$, as determined by the Trypan blue exclusion assay.

\section{Cell attachment on 2D films}

Four types of surface-modified PLLA films, namely, DI00, DI20, DI40, and DI60, were prepared in dioxane/water solvent mixture with a dioxane volume percent of $0 \%, 20 \%$, $40 \%$, and $60 \%$ in the solvent mixture, respectively, and used for cell attachment experiments. These films were assembled on the bottoms of custom-made 12-well Teflon plates with a well diameter of $10 \mathrm{~mm}$. The film-containing culture plates were sterilized with ethylene oxide for $24 \mathrm{~h}$. The sterilized films were soaked in ethanol for $30 \mathrm{~min}$, exchanged with $1 \%$ PBS solution for $30 \mathrm{~min}$, and then washed twice with $\alpha$-MEM (with 10\% FBS and 1\% antibiotics). Each film was seeded with $1 \times 10^{4}$ cells and cultured at $37^{\circ} \mathrm{C}$ with $5 \% \mathrm{CO}_{2}$. The cells were detached by adding $0.05 \%$ trypsin and 0.53 mM EDTA $4 \mathrm{~h}$ after cell seeding and were counted using a hemocytometer.

\section{Cell adhesion and proliferation on gelatin- modified scaffolds}

Three types of scaffolds, namely, PLLA scaffolds (control), surface-modified PLLA scaffolds by physical entrapment, and surface-modified PLLA scaffolds by chemical crosslinking after physical entrapment, were prepared for cell attachment and proliferation. The scaffold-containing culture flasks were sterilized with ethylene oxide for $24 \mathrm{~h}$. The scaffolds were soaked in ethanol for $30 \mathrm{~min}$ and then exchanged three times with PBS. The scaffolds were washed twice with a complete medium ( $\alpha$-MEM, 10\% FBS, $1 \%$ antibiotics, and additional $50 \mathrm{mg} / \mathrm{L}$ of L-ascorbic acid and 80 $\mathrm{mM} \beta$-glycerophosphate). Cells $\left(5 \times 10^{5}\right)$ suspended in $2 \mathrm{~mL}$ of complete medium were seeded on each scaffold. They were cultured in $25-\mathrm{cm}^{2}$ tissue culture flasks on an orbital shaker (Model 3520; Lab-Line Instrument, Melrose Park, IL) at $100 \mathrm{rpm}$ in a humidified incubator at $37^{\circ} \mathrm{C}$ with $5 \% \mathrm{CO}_{2}$. The cell-scaffold constructs were removed from the tissue culture flasks and transferred into six-well tissue culture plates $24 \mathrm{~h}$ after cell seeding. The constructs were cultured with the complete medium on the orbital shaker at $50 \mathrm{rpm}$ in the humidified incubator at $37^{\circ} \mathrm{C}$ with $5 \% \mathrm{CO}_{2}$. Four milliliters of medium was used for each construct, and the medium was changed every other day. Total DNA amounts were measured 1 day and 4 weeks after cell seeding.

\section{DNA assay}

Cell numbers on the scaffold were determined using a DNA assay. The cell-scaffold constructs were homogenized using a Polytron homogenizer (Brinkmann Easycare Generator; Polytron-Aggregate, Switzerland) for $30 \mathrm{~s}$ at top speed (VI) three times before DNA isolation. Using fluorescence 
assay with Hoechst 33258 dye, DNA assays were performed 1 day and 4 weeks after cell seeding.

\section{Cell morphology}

After having been cultured for 4 weeks, the scaffolds were taken out of the culture plates and washed three times with PBS. The samples were fixed with 3\% glutaraldehyde in PBS at $4^{\circ} \mathrm{C}$ for $24 \mathrm{~h}$. After being thoroughly washed with PBS, the samples were treated with $1 \%$ osmium tetraoxide in $0.1 \mathrm{M}$ cacodylate buffer for $1 \mathrm{~h}$ and then washed with PBS. The samples were dehydrated sequentially in 50\%, 60\%, 70\%, $80 \%, 90 \%$, and $100 \%$ ethanol for $30 \mathrm{~min}$ each and then critical-point-dried with HMDS. The dried samples were sliced evenly into two 1-mm-thick pieces. The sliced side of the scaffolds was coated with gold and analyzed with SEM. A domain around $1.0 \mathrm{~mm}$ from the perimeter of the cylindrical sample was selected for SEM observation.

\section{Statistical analysis}

All data were presented as means \pm standard deviations (SD). To test the significance of observed differences between the study groups, an unpaired Student's t test (twotail) was applied. A value of $p<0.05$ was considered to be statistically significant.

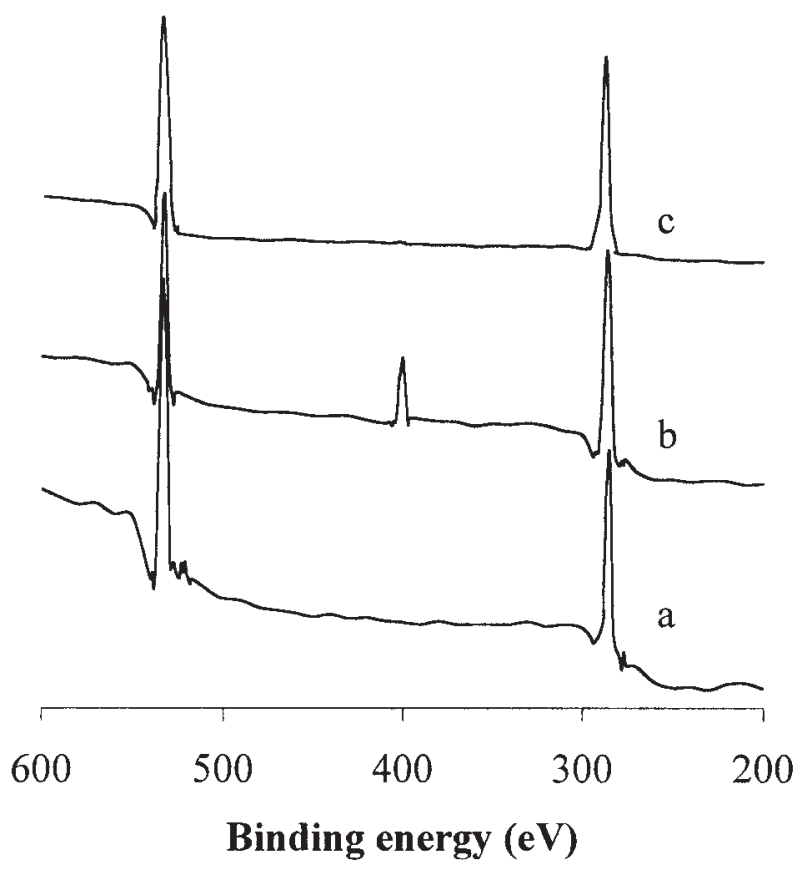

Figure 1. The XPS survey scan spectrum of simply coated PLLA surface: (a) control; (b) immersed in aqueous gelatin solution (3.0 g/L) for $10 \mathrm{~min}$; (c) immersed in aqueous gelatin solution $(3.0 \mathrm{~g} / \mathrm{L})$ for $10 \mathrm{~min}$, then rinsed in water at $40^{\circ} \mathrm{C}$ for $12 \mathrm{~h}$.

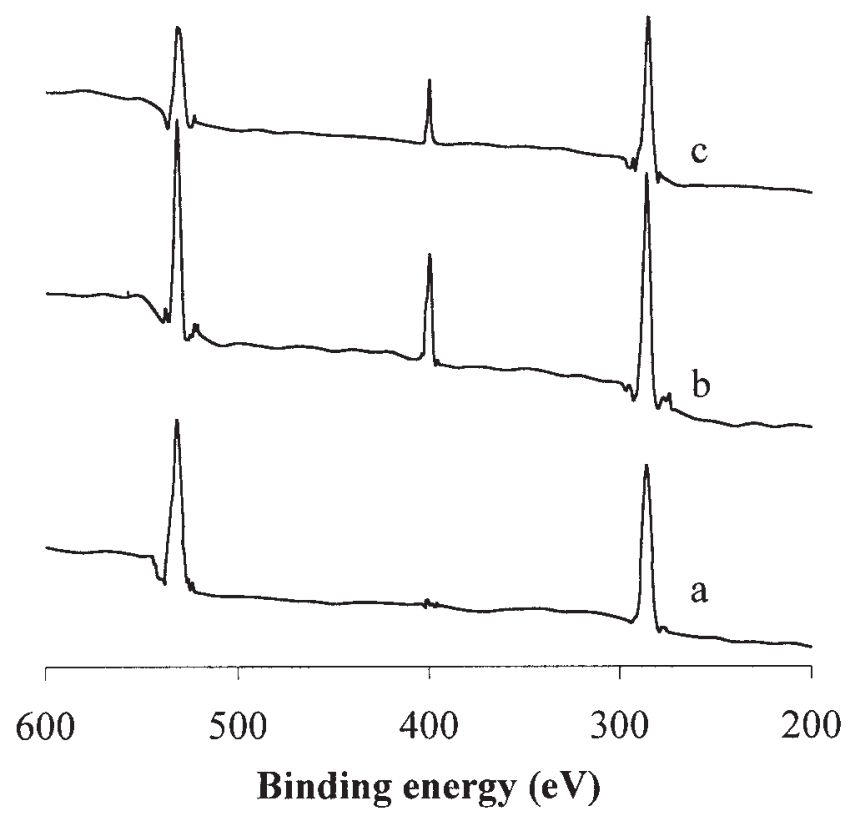

Figure 2. The XPS survey scan spectrum of surface entrapped PLLA films: (a) control; (b) immersed in $3.0 \mathrm{~g} / \mathrm{L}$ gelatin solution (dioxane/water $=60 / 40$ ) for $10 \mathrm{~min}$; (c) immersed in $3.0 \mathrm{~g} / \mathrm{L}$ gelatin solution (dioxane/water = $60 / 40$ ) for $10 \mathrm{~min}$, then rinsed in water at $40^{\circ} \mathrm{C}$ for $12 \mathrm{~h}$.

\section{RESULTS}

An aqueous gelatin solution was used to examine the effect of simple physical adsorption or deposition of gelatin on PLLA film surface. The XPS measurement revealed that a visible new peak at binding energy of $400.0 \mathrm{eV}$ appeared after simply immersing PLLA films in an aqueous gelatin solution (Fig. 1). The peak at binding energy of $400.0 \mathrm{eV}$ corresponds to nitrogen element of gelatin molecules. However, the peak disappeared after the sample was rinsed in distilled water at $40^{\circ} \mathrm{C}$, indicating that the adsorbed gelatin left the surface of PLLA films and dissolved in water.

Nitrogen peak at binding energy of $400.0 \mathrm{eV}$ appeared after the PLLA film was immersed in gelatin solution [dioxane/water $=60 / 40(\mathrm{v} / \mathrm{v}) ;$ Fig. 2]. The peak remained after the gelatin-entrapped PLLA film was rinsed in distilled water at $40^{\circ} \mathrm{C}$ for $12 \mathrm{~h}$, although the peak strength decreased. The decrease of peak strength resulted from the dissolution of simply deposited gelatin molecules on the PLLA film surface. In the ATR-FTIR spectra, two new vibration peaks at 1528 and $1636 \mathrm{~cm}^{-1}$ appeared after the PLLA film was immersed in gelatin solution (Fig. 3). These two peaks were the amide bond absorption of gelatin, and their strength decreased when the PLLA film was rinsed in water at $40^{\circ} \mathrm{C}$. Both results indicated that gelatin was successfully entrapped onto the PLLA film surface.

The amount of nitrogen on the surface of gelatin- 


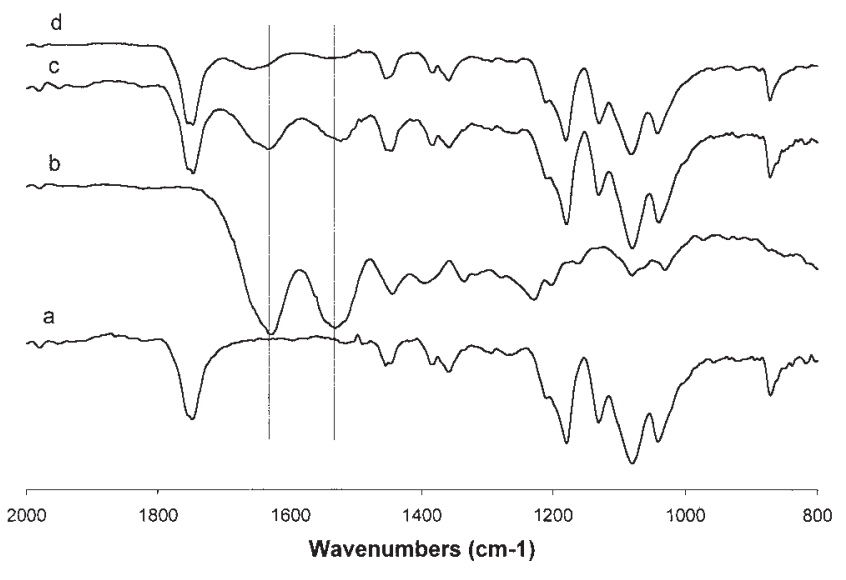

Figure 3. The ATR-FTIR spectra of surface-modified PLLA films: (a) PLLA film; (b) gelatin; (c) immersed in $3.0 \mathrm{~g} / \mathrm{L}$ gelatin solution (dioxane/water $=60 / 40$ ) for $10 \mathrm{~min}$; (d) immersed in $3.0 \mathrm{~g} / \mathrm{L}$ gelatin solution (dioxane/water = $60 / 40$ ) for $10 \mathrm{~min}$, then rinsed in water at $40^{\circ} \mathrm{C}$ for $12 \mathrm{~h}$.

modified PLLA film increased with the ratio of dioxane/water used (Table I). For surface-modified PLLA films with chemical crosslinking after physical entrapment, the amount of entrapped gelatin on the surface was significantly increased (Table II). The amount of nitrogen reached $12.4 \%$ for the PLLA film treated with chemical crosslinking after physical entrapment in $60 / 40$ (v/v) dioxane/water solvent mixture, whereas the nitrogen amount was $6.3 \%$ when only physical entrapment was applied. The amounts of gelatin entrapped on PLGA films were always higher than that on PLLA films when the same gelatin solution was used. This seemed to indicate that an amorphous polymer (PLGA) allowed more entangles to form than did a semicrystalline polymer (PLLA).

The amount of nitrogen on the PLLA film surface increased from $5.2 \%$ to $12.4 \%$ as immersing time increased from $1 \mathrm{~min}$ to $10 \mathrm{~min}$ (Table III). Further increasing the immersing time had little effect on the amount of entrapped gelatin.

The surface wettability changed as the poly( $\alpha$-hydroxy acids) surfaces were modified with gelatin (Fig. 4). The contact angle decreased when PLLA films were

TABLE I

Effect of Solvent Composition on the Amount of Entrapped Gelatin on PLLA Films ${ }^{a}$

\begin{tabular}{lcc}
\hline Polymer & $\begin{array}{c}\text { Dioxane } / \mathrm{H}_{2} \mathrm{O} \\
(\mathrm{v} / \mathrm{v})\end{array}$ & $\mathrm{N}($ at $\%)$ \\
\hline \multirow{3}{*}{ PLLA } & $0 / 100$ & 1.1 \\
& $20 / 80$ & 2.7 \\
& $40 / 60$ & 5.1 \\
$60 / 40$ & 6.3 \\
\hline
\end{tabular}

a The PLLA films were immersed in $3.0 \mathrm{~g} / \mathrm{L}$ gelatin solution for $10 \mathrm{~min}$, followed by rinsing in water at $40^{\circ} \mathrm{C}$ for $12 \mathrm{~h}$.
TABLE II

Amount of Gelatin on Polymer Films (PLLA and PLGA) After Physical Entrapment (Immersed in $3.0 \mathrm{~g} / \mathrm{L}$ Gelatin Solution for $10 \mathrm{~min}$ ) and Chemical Crosslinking

\begin{tabular}{lcc}
\hline Polymers & $\begin{array}{c}\text { Dioxane } / \mathrm{H}_{2} \mathrm{O} \\
(\mathrm{v} / \mathrm{v})\end{array}$ & $\mathrm{N}(\mathrm{at} \%)$ \\
\hline \multirow{3}{*}{ PLLA } & $0 / 100$ & 1.2 \\
& $20 / 80$ & 4.5 \\
& $40 / 60$ & 8.9 \\
PLGA85 & $60 / 40$ & 12.4 \\
& $10 / 90$ & 6.8 \\
& $20 / 80$ & 8.1 \\
& $30 / 70$ & 10.2 \\
\hline
\end{tabular}

entrapped with gelatin, indicating the enhanced hydrophilicity of surface-modified PLLA films.

The cell numbers on the gelatin-modified PLLA films (DI40 and DI60) were significantly higher than that on the control (DI00) (Fig. 5). Increasing the amount of entrapped gelatin on the film surface improved cell adhesion.

The DNA content of the cell-scaffold constructs was measured to quantify the osteoblast adhesion and proliferation on the surface-modified scaffolds and control scaffolds (Fig. 6). The DNA amount on the surface-modified PLLA scaffold (physical entrapment followed by chemical crosslinking) was significantly higher than that on the control scaffold after 1 day of cell seeding $(p<0.05)$. The DNA amount on the surface-modified scaffolds (including both physical entrapment and chemical crosslinking after physical entrapment) was significantly greater than that on the PLLA control 28 days after cell seeding. In addition, the DNA amount on the surface-modified scaffold with only physical entrapment was significantly lower than that on the surface-modified scaffold with physical entrapment followed by chemical crosslinking $(p<0.05)$.

The SEM images of osteoblasts cultured on the surface-modified PLLA scaffolds and control scaffolds were taken 4 weeks after cell seeding (Fig. 7). More collagen fibers and other cell secretions were observed on the surface-modified scaffolds than on the control. In surface-modified scaffolds with chemical crosslinking, secreted collagens were bound together to form

TABLE III

Effect of Entrapment Time on the Amount of Entrapped Gelatin on PLLA Films ${ }^{a}$

\begin{tabular}{cc}
\hline Entrapment time $(\mathrm{min})$ & $\mathrm{N}(\mathrm{at} \%)$ \\
\hline 1 & 5.2 \\
5 & 9.7 \\
10 & 12.4 \\
60 & 12.8
\end{tabular}

${ }^{a}$ The PLLA films were immersed in $3.0 \mathrm{~g} / \mathrm{L}$ gelatin solution $($ dioxane/water $=60 / 40(\mathrm{v} / \mathrm{v})$ ) followed by chemical crosslinking. 


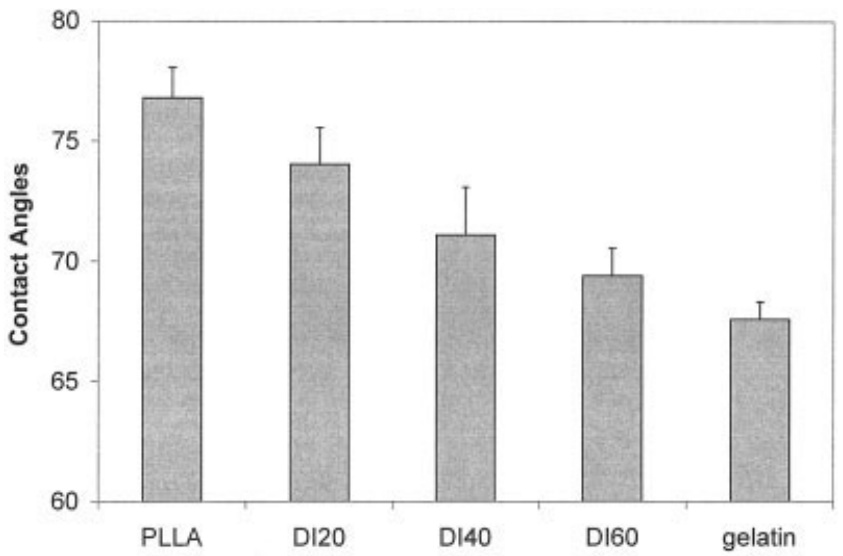

Figure 4. The effect of solvent composition on contact angles of surface-modified PLLA films. The PLLA films were immersed in $3.0 \mathrm{~g} / \mathrm{L}$ gelatin solution for $10 \mathrm{~min}$, followed by rinsing at $40^{\circ} \mathrm{C}$ for $12 \mathrm{~h}$.

large collagen bundles as a result of increased fiber density [Fig. 7(c,d)].

\section{DISCUSSION}

Simple coating is an uncomplicated and commonly used surface modification method. However, the main shortcomings of this method are its low efficiency and surface instability. Although gelatin molecules could deposit on poly( $\alpha$-hydroxy acids) surface when a poly( $\alpha$-hydroxy acids) film or scaffold was immersed in an aqueous gelatin solution, the adsorption of gelatin was not stable. When rinsed in distilled water above the gelation temperature, the adsorbed gelatin molecules on the film or scaffold surface were dissolved, leaving behind an uncoated surface.

The main difference of surface modification by entrapment from simple coating was the use of a solvent mixture. For the poly( $\alpha$-hydroxy acids)-gelatin sys-

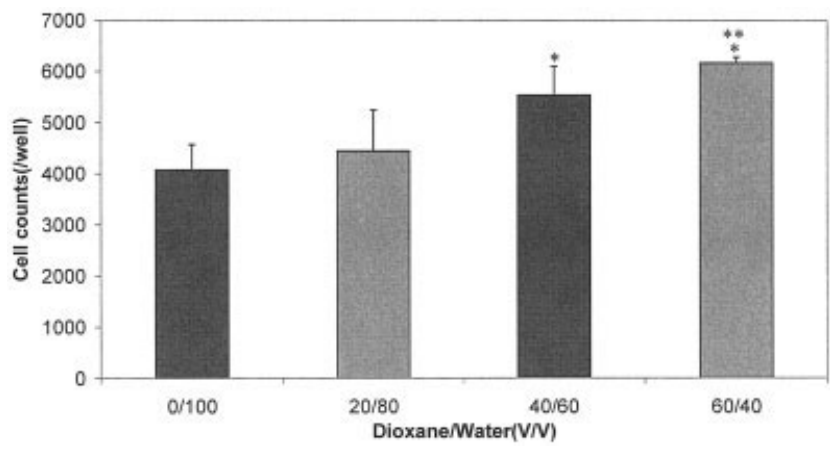

Figure 5. The attached numbers of MC3T3E1 osteoblasts $4 \mathrm{~h}$ after cell seeding. Cells $\left(1 \times 10^{4}\right)$ were seeded on each film. Cell numbers were measured using a hemocytometer. (Statistical significance: ${ }^{*} p<0.05$ compared with the control group DI00; ${ }^{* *} p<0.05$ compared with DI20.)

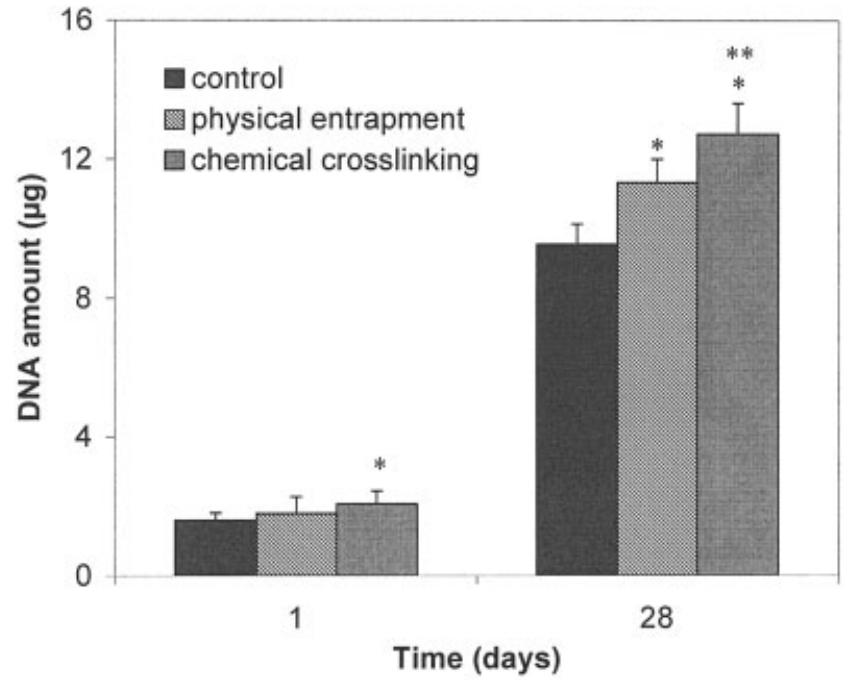

Figure 6. The DNA amounts in the PLLA scaffolds (control group) and gelatin-modified PLLA scaffolds according to cultivating time. Cells $\left(5 \times 10^{5}\right)$ were seeded into each scaffold. (Statistical significance: ${ }^{*} p<0.05$ compared with the control group; ${ }^{* *} p<0.05$ compared with the surface physical entrapment group.

tem, a mixture of dioxane and water was selected as the solvent system. The solvent mixture composition was chosen such that gelatin was soluble in the solvent mixture, while the poly ( $\alpha$-hydroxy acids) swelled but did not dissolve in the solvent mixture. When a poly( $\alpha$-hydroxy acids) film or scaffold was immersed in the gelatin/dioxane/water mixture, gelatin molecules diffused onto the swollen surface of the polymer and were entangled with polymer molecules on the surface. As the surface-swollen polymer was removed from gelatin solution and quickly dipped into cold water, a nonsolvent for the polymer, the surface rapidly shrank and gelatin molecules on the polymer surface were entrapped and immobilized. The entrapped gelatin was stable and did not dissolve when rinsed in water at $40^{\circ} \mathrm{C}$. This is a simple and universally effective method for surface modification. No functional groups in polymer chains are needed for this surface modification method. In contrast to the method of incorporating modifying groups by copolymerization, the entrapment method maintains the bulk properties of materials. As the modifying molecules only gather on the surface of materials, the efficiency is high for surface modification. In addition, the entrapment method can be used for any geometry, morphology, and thickness of 3D scaffold, which is a limitation for some other surface modification methods (for example, surface treatment with plasma). Furthermore, the entrapment method allows us to modify the surface in a controlled fashion because various parameters (solvent ratio, gelatin concentration, immersing time, and chemical crosslinking) can be varied to tailor the process. 


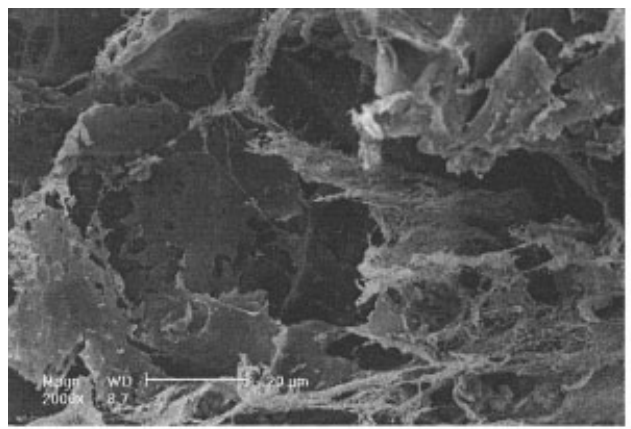

(a)

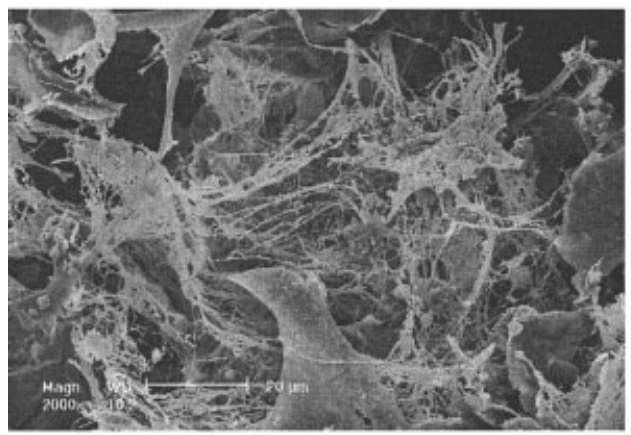

(c)

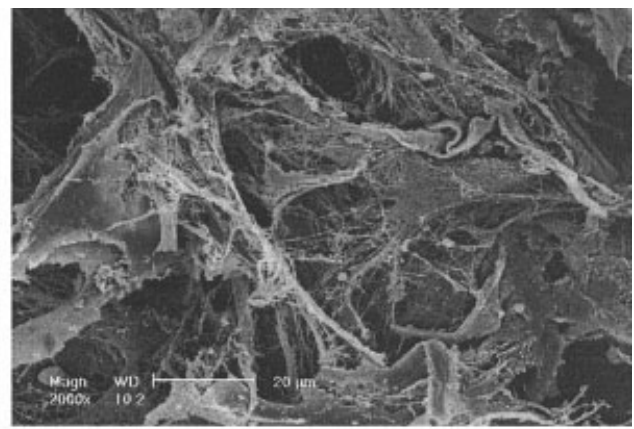

(b)

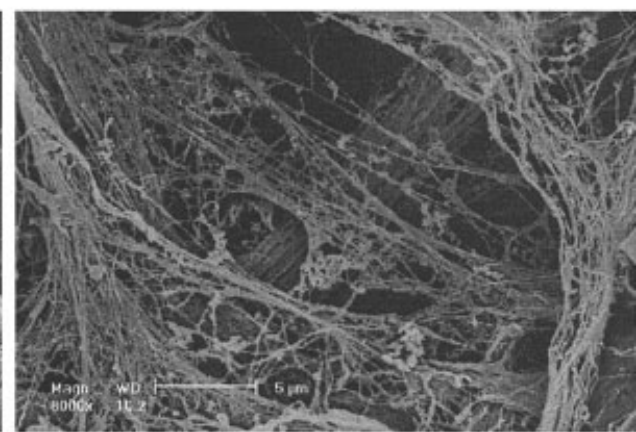

(d)

Figure 7. The SEM images of PLLA scaffolds 4 weeks after cell seeding: (a) PLLA control; (b) physical entrapment in 3.0 $\mathrm{g} / \mathrm{L}$ gelatin solution (dioxane/water $=60 / 40$ ) for $10 \mathrm{~min}$; (c) chemical crosslinking following the physical entrapment; (d) chemical crosslinking [high magnification of (c)].

Dioxane is a good solvent for PLLA and PLGA, and the interaction between the polymer and solvent mixture increases with the ratio of dioxane in the solvent mixture. The stronger interaction leads to a more swollen surface, thus allowing more gelatin molecules to enter the swollen surface and be entrapped. Therefore, the amount of entrapped gelatin on the polymer surface increased with the ratio of dioxane/water. The gelatin amount on the PLLA surface was highest when the dioxane ratio in solvent composition reached $60 \%$. Further increasing dioxane in the solvent mixture led to the insolubility of gelatin, and the process of entrapment could not be performed.

Chemical crosslinking after physical entrapment was utilized to further increase the amount of gelatin on the surface. When the polymer sample was quenched in cold water, there were some gelatin molecules that were not entrapped on the polymer surface but were entangled with the entrapped gelatin molecules. These gelatin molecules would be washed away when rinsed in warm water. Chemical crosslinking immobilized these gelatin molecules, increasing the amount of gelatin on the polymer surface.

Gelatin is more hydrophilic than is PLLA, thus the decrease of contact angles after surface modification indicated that gelatin molecules were successfully incorporated onto the PLLA surface. The lower contact angle indicated higher gelatin amount on the surface.
The gelatin-modified porous PLLA and PLGA scaffolds combine the advantages of both synthetic and natural materials. Synthetic PLLA provides the mechanical strength and controllable degradation rate. Gelatin is known to promote cell adhesion and proliferation. ${ }^{26,28}$ Statistically, more cells attached on the surface-modified 2D films and 3D scaffolds than on the controls (Figs. 5 and 6). The cells attached on the films or scaffolds increased with increasing amount of gelatin. Cell proliferation was higher on the surfacemodified scaffolds than on the control scaffolds, and the proliferation rate increased with the amount of gelatin on the scaffold surface. More extracellular matrix (ECM) was secreted by cells in surface-modified scaffolds than in the controls. All these results demonstrated that surface-modified scaffolds are superior to control scaffolds.

\section{CONCLUSIONS}

A novel treatment procedure has been developed for surface modification of porous polymer scaffolds. Gelatin was successfully entrapped onto the surface of poly( $\alpha$-hydroxy acids) films and scaffolds by a procedure that involved soaking polymer films and scaffolds in solutions of gelatin in dioxane/water mix- 
tures. Control over the amount of entrapped gelatin was achieved by varying the solvent composition, the duration of soaking, the concentration of gelatin solution, and chemical crosslinking. The hydrophilicity increased with the amount of entrapped gelatin. The surface modification significantly improved cell attachment and proliferation. More collagen fibers and other cell secretions were observed in the surfacemodified scaffolds than in the control scaffolds. This novel surface treatment strategy provided a convenient and universal way to modify the surface properties of porous scaffolds and thus promote cell adhesion and proliferation for tissue engineering.

The authors acknowledge the financial support from the University of Michigan [Nano Materials Initiative Grant (P.X.M.)] and the National Institutes of Health [Research Grants DE014755 and DE015384 (P.X.M.)].

\section{References}

1. Ma PX. Scaffolds for tissue fabrication. Materials Today 2004; 7:30-40

2. Shi H, Ratner BD. Template recognition of protein-imprinted polymer surfaces. J Biomed Mater Res 2000;49:1-11

3. Boyan BD, Hummert TW, Dean DD, Schwartz Z. Role of material surfaces in regulating bone and cartilage cell response. Biomaterials 1996;17:137-146.

4. Ito Y. Surface micropatterning to regulate cell functions. Biomaterials 1999;20:2333-2342

5. Mann BK, Tsai AT, Scott-Burden T, West JL. Modification of surfaces with cell adhesion peptides alters extracellular matrix deposition. Biomaterials 1999;20:2281-2286.

6. Hench LL, Polak JM. Third-generation biomedical materials. Science 2002;295:1014-1017.

7. Ma PX, Tissue engineering. In Kroschwitz JI, editor. Encyclopedia of polymer science and technology. Hoboken: John Wiley \& Sons, Inc.; 2003. URL: www.mrw.interscience.wiley. com/epst.

8. Hubbell JA, Bioactive biomaterials. Curr Opin Biotechnology 1999;10:123-129.

9. Ma PX, Zhang RY, Xiao GZ, Franceschi R. Engineering new bone tissue in vitro on highly porous poly(alpha-hydroxyl acids)/hydroxyapatite composite scaffolds. J Biomed Mater Res 2001;54:284-293.

10. Chapekar MS. Tissue engineering: Challenges and opportunities. J Biomed Mater Res 2000;53:617-620.

11. Woo KM, Chen VJ, Ma PX. Nano-fibrous scaffolding architecture selectively enhances protein adsorption contributing to cell attachment. J Biomed Mater Res 2003;67A:531-537.

12. Chen VJ, Ma PX. Nano-fibrous poly(L-lactic acid) scaffolds with interconnected spherical macropores. Biomaterials 2004; 25:2065-2073.

13. Ma PX, Zhang RY. Microtubular architecture of biodegradable polymer scaffolds. J Biomed Mater Res 2001;56:469-477.
14. Ma PX, Schloo B, Mooney D, Langer R. Development of biomechanical properties and morphogenesis of in-vitro tissue engineered cartilage. J Biomed Mater Res1995;29:1587-1595.

15. Dean D, Topham NS, Meneghetti SC, Wolfe MS, Jepsen K, He S, Chen JE, Fisher JP, Cooke M, Rimnac C, Mikos AG. Poly(propylene fumarate) and poly(DL-lactic-co-glycolic acid) as scaffold materials for solid and foam-coated composite tissue-engineered constructs for cranial reconstruction. Tissue Eng 2003;9:495-504.

16. Seidel JO, Pei M, Gray ML, Langer R, Freed LE, VunjakNovakovic G. Long-term culture of tissue engineered cartilage in a perfused chamber with mechanical stimulation. Biorheology 2004;41:445-458.

17. Pollok JM, Kluth D, Cusick RA, Lee H, Utsunomiya H, Ma PX, Langer R, Broelsch CE, Vacanti JP. Formation of spheroidal aggregates of hepatocytes on biodegradable polymers under continuous-flow bioreactor conditions. Eur J Pediatr Surg 1998; 8:195-199.

18. Ito $\mathrm{T}$, Nakamura $\mathrm{T}$, Takagi $\mathrm{T}$, Toba $\mathrm{T}$, Hagiwara A, Yamagishi $\mathrm{H}$, and Shimizu Y. Biodegradation of polyglycolic acid-collagen composite tubes for nerve guide in the peritoneal cavity. ASAIO Journal 2003;49:417-421.

19. Cai KY, Yao KD, Cui YL, Lin SB, Yang ZM, Li XQ, Xie HQ, Qing TW, Luo J. Surface modification of poly (D,L-lactic acid) with chitosan and its effects on the culture of osteoblasts in vitro. J Biomed Mater Res 2002;60:398-404.

20. Zhang RY, Ma PX. Porous poly(L-lactic acid)/apatite composites created by biomimetic process. J Biomed Mater Res 1999; 45:285-293.

21. Zhang R, Ma PX. Biomimetic polymer/apatite composite scaffolds for mineralized tissue engineering. Macromol Biosci 2004;4:100-111.

22. Ma PX, Zhang R. Porous composite materials. US Patent $6,281,257$ (2001).

23. $\mathrm{Hu} \mathrm{YH}$, Winn SR, Krajbich I, Hollinger JO. Porous polymer scaffolds surface-modified with arginine-glycine-aspartic acid enhance bone cell attachment and differentiation in vitro. J Biomed Mater Res Part A 2003;64A:583-590.

24. Hrkach JS, Ou J, Lotan N, Langer R. Synthesis of poly(L-lactic acid-co-L-lysine) graft-copolymers. Macromolecules 1995;28: $4736-4739$.

25. Nitschke M, Schmack G, Janke A, Simon F, Pleul D, Werner C. Low pressure plasma treatment of poly(3-hydroxybutyrate): Toward tailored polymer surfaces for tissue engineering scaffolds. J Biomed Mater Res 2002;59:632-638.

26. Rose PI. Gelatin. In Mark HF, Bikales NM, Overberger CG, Menges G, Kroschwitz JI, editors. Encyclopedia of polymer science and engineering. New York: John Wiley \& Sons; 1987. p 488-513.

27. Thomson RC, Yaszemski MJ, Powers JM, Mikos AG. Fabrication of biodegradable polymer scaffolds to engineer trabecular bone. J Biomater Sci Polym Ed. 1995;7:23-38.

28. Muniruzzaman M, Tabata Y, Ikada Y. Protein interaction with gelatin hydrogels for tissue engineering. Mater Sci Forum 1997; 50:89-96.

29. Ren L, Tsuru K, Hayakawa S, Osaka, A. Novel approach to fabricate porous gelatin-siloxane hybrids for bone tissue engineering. Biomaterials 2002;23:4765-4773.

30. Ma PX, Choi JW. Biodegradable polymer scaffolds with welldefined interconnected spherical pore network. Tissue Eng 2001;7:23-33. 